\title{
Pengaruh Pola Aliran Komunikasi Organisasi Terhadap Motivasi Kerja Karyawan (Studi Kasus pada Divisi IT di Blibli.com)
}

\author{
Giovani Chieristian, Diah Ayu Candraningrum \\ vanichie16@gmail.com,diahc@fikom.untar.ac.id \\ Fakultas Ilmu Komunikasi Universitas Tarumanagara
}

\begin{abstract}
Blibli.com is one of the e-commerce in Indonesia in the digital sector. Blibli.com is the first product from PT. Global Digital Niaga which is a subsidiary of Djarum Foundation. The concept used by Blibli is online shopping but people feel like shopping at a mall, so they don't need to the mall when they want to buy something. People can download Blibli.com in their phone, because Blibli.com is the application on smartphone. Researcher want to research on communication that occurs in the IT division because IT division plays an important roles in the Blibli application activities. I want to find out whether the communication established in the IT divison in Blibli.com was able to influence the work motivation of employees or not. This research aims to determine the relationship between communication and motivation so $i$ choose IT division as the respondent in this research. This research is tested quantitatively, using the survey method. The result of this research conclusions are based on a simple linear regression test, shows that organizational communication that occurs has a significant influence on the employee motivation at Blibli.com.
\end{abstract}

Keywords: organizational communication, work motivation, applications, digital media, ecommerce

\begin{abstract}
Abstrak
Blibli.com adalah salah satu e-commerce di Indonesia. Blibli sendiri adalah produk pertama dari PT. Global Digial Niaga yang merupakan anak perusahaan dari Djarum. Konsep yang dipakai Blibli adalah belanja online sepertihalnya belanja dalam mall, sehingga masyarakat tidak perlu lagi untuk pergi ke mall jika ingin berbelanja. Blibli.com berbentuk aplikasi yang terdapat di ponsel (mobile apps). Peneliti melakukan penelitian tentang komunikasi organisasi yang terjadi di divisi IT Blibli.com, karena divisi IT berperan penting dalam aktivitas aplikasi Blibli.com. Peneliti juga ingin mengetahui apakah komunikasi yang terjalin dalam divisi IT di Blibli mampu mempengaruhi motivasi kerja para karyawan atau tidak. Peneliti memilih divisi IT sebagai objek penelitian karena peneliti ingin mengetahui lebih spesifik dan dikarenakan Blibli.com berbasis applikasi sehingga peneliti memilih divisi IT untuk dijadikan sampel dalam penelitian ini. Penelitian ini menggunakan pendekatan kuantitatif dengan metode survey. Berdasarkan uji regresi liner sederhana, menunjukkan bahwa komunikasi organisasi yang terjadi memiliki pengaruh signifikan terhadap motivasi kerja karyawan di Blibli.com.
\end{abstract}

Kata Kunci: komunikasi organisasi, motivasi kerja, aplikasi, media digital, e-commerce

\section{Pendahuluan}

Komunikasi adalah proses sosial dimana masyarakat menggunakan simbolsimbol untuk menciptakan dan menginterpretasikan makna dalam lingkungan mereka (West dan Turner, 2008). Selain komunikasi, perkembangan teknologi juga sudah semakin canggih dan akan terus berkembang. Hal tersebut juga sudah melekat dengan masyarakat karena teknologi sangat membantu manusia dalam kehidupan sehari-hari. 
Melihat manusia dan teknologi memiliki hubungan yang sangat erat, banyak perusahaan yang akhirnya memutuskan untuk memanfaatkan teknologi ini untuk mengembangkan bisnis mereka. Banyak perusahaan yang menggunakan internet sebagai media promosi dan memasarkan usahanya secara online dikarenakan lebih efektif dan lebih mudah.

Menurut Pace dan Faules (2011) komunikasi organisasi yang terjalin baik secara vertikal maupun horizontal sering terjadi kendala yang akhirnya menyebabkan ketidaklancaran dalam berkomunikasi atau dengan kata lain terjadinya miss communication. Oleh sebab itu, setiap perusahaan perlu menjaga alur komunikasi dengan setiap anggotanya agar tercipta komunikasi yang efektif. Komunikasi yang efektif akan terjadi ketika pesan yang disampaikan oleh komunikator bisa diterima dengan baik oleh komunikan dan komunikan tersebut memberikan feedback atas pesan yang diterima.

Dengan terciptanya komunikasi yang efektif, hubungan antara anggota dalam sebuah organisasi juga akan terjalin dengan baik sehingga akan menciptakan lingkungan kerja yang positif dan komunikasi yang lebih terbuka diantara atasan dengan bawahan maupun dengan sesama karyawan.

Motivasi merupakan dorongan untuk bertindak terhadap serangkaian proses perilaku manusia dengan mempertimbangkan arah, intensitas, dan ketekunan pada pencapaian tujuan (Wibowo, 2013). Menurut Mangkunegara (2013) motivasi bisa terbentuk dari sikap dan perilaku karyawan dalam menghadapi lingkungan kerja dalam perusahaan.

Komunikasi organisasi dengan motivasi biasanya memiliki keterkaitan dengan bagaimana komunikasi yang terjalin dalam organisasi tersebut sehingga para karyawan dapat mengerti pesan yang disampaikan oleh anggota lainnya. Komunikasi juga sebenarnya dapat menjaga motivasi karyawan dengan cara menjelaskan kepada mereka apa yang harus mereka kerjakan, bagaimana kinerja kerja mereka dan keuntungan apa yang mereka dapatkan jika kinerja kerja karyawan tersebut memuaskan.

Peneliti bermaksud mengetahui bagaimana motivasi yang terbentuk dari aliran komunikasi dalam suatu perusahaan. Salah satu perusahaan yang sudah memiliki karyawan yang cukup banyak ialah Blibli.com. Blibli.com sudah berdiri sejak tahun 2009 dan merupakan salah satu anak perusahaan dari Djarum Foundation. Blibli.com sendiri merupakan salah satu produk pertama yang dihasilkan oleh PT. Global Digital Niaga dalam bidang digital yang berbentuk e-commerce.

Blibli.com merupakan salah satu e-commerce yang ada di Indonesia dengan mengusung konsep belanja online seperti belanja di mall. Dengan konsep yang diterapkan tersebut, Blibli.com sendiri mempunyai harapan bahwa masyarakat di Indonesia yang biasanya berbelanja di mall kini bisa lebih mudah dengan adanya sistem belanja online yang lebih efektif dan efisien karena bisa dilakukan dimanapun dan kapanpun mereka mau (www.telkomuniversity.ac.id).

Oleh sebab itu, peneliti ingin melihat dan mengetahui apakah komunikasi dapat mempengaruhi motivasi kerja karyawan dalam suatu perusahaan. Peneliti ingin melihat bagaimana motivasi yang diberikan oleh perusahaan kepada karyawannya untuk meningkatkan kinerja para pekerjanya. Karena itu, peneliti ingin melaksanakan penelitian mengenai "Pengaruh Pola Aliran Komunikasi Organisasi Terhadap Motivasi Kerja Karyawan (Studi Kasus Divisi IT Blibli.com)"

Adapun dalam penelitian ini penulis juga telah merumuskan masalah yaitu "Bagaimana Pengaruh Pola Aliran Komunikasi Organisasi Terhadap Motivasi Kerja 
Karyawan di Blibli.com?" dengan hipotesis Ho yaitu tidak terdapat pengaruh komunikasi organisasi terhadap motivasi kerja karyawan di Blibli.com dan Ha yaitu terdapat pengaruh komunikasi organisasi terhadap motivasi kerja karyawan di Blibli.com. Tujuan dari penelitian ini adalah untuk mengetahui apakah terdapat pengaruh antara pola aliran komunikasi organisasi dengan motivasi kerja karyawan di Blibli.com khususnya pada divisi IT.

\section{Metode Penelitian}

Penelitian ini menggunakan pendekatan penelitian kuantitatif. Penelitian kuantitatif adalah penelitian yang menggambarkan atau menjelaskan suatu informasi yang hasil penelitiannya dapat digeneralisasikan (Kriyantono, 2012). Dalam penelitian ini, peneliti menggunakan paradigma sederhana, dimana paradigma ini terdiri atas satu variabel independen (Komunikasi Organisasi) dan variabel dependen (Motivasi Kerja) (Sugiyono, 2011). Hasil dalam penelitian kuantitatif berupa angka dan bisa diukur dan peneliti menggunakan penelitian kuantitatif untuk mencari pengaruh dari komunikasi organisasi terhadap motivasi kerja di Blibli.com.

Metode penelitian yang digunakan adalah metode survei eksplanatif dengan sifat asosiatif. Survey eksplanatif (analitik) adalah survei yang digunakan untuk mengetahui mengapa situasi atau kondisi tertentu terjadi atau apa yang mempengaruhi terjadinya sesuatu. Sedangkan asosiatif adalah survei yang menjelaskan hubungan (korelasi) antar variabel (Kriyantono, 2012).

Data yang akan dikumpulkan menggunakan kuesioner sebagai instrumen pengumpulan data. Kuesioner adalah daftar pertanyaan yang harus diisoi oleh responden. Kuesioner yang digunakan adalah kuesioner tertutup yang dimana kuesioner tersebut telah diberikan alternatif jawaban oleh periset dan responden tinggal memilih jawaban yang sudah diberikan sesuai dengan apa yang terjadi (Kriyantono, 2012:97-98). Kuesioner dibagikan melalui chatting.

Peneliti melakukan survei terhadap karyawan Blibli.com yang bekerja pada divisi IT. Untuk menentukan jumlah sampel, digunakan teknik accidental sampling dimana periset memilih siapa saja karyawan yang kebetulan dijumpai untuk dijadikan sampel. Karyawan Blibli.com pada divisi IT berjumlah 50 orang dan untuk mendapatkan total sampel peneliti menggunakan rumus Slovin dan didapatkan hasil yaitu:

$$
n=45 \text { orang }
$$

Adapun indikator dari Komunikasi Organisasi yang diteliti adalah sebagai berikut:

1. Pimpinan memberikan instruksi jelas mengenai tugas yang harus dikerjakan.

2. Pimpinan memberikan pujian kepada karyawan atas prestasi yang dicapai.

3. Pimpinan memberikan teguran atau nasihat kepada karyawan yang lalai mengerjakan tugasnya.

4. Menggunakan media online dalam penyebaran informasi.

5. Karyawan harus menyampaikan laporan hasil pekerjaannya kepada pimpinan.

6. Menyampaikan masalah tentang pekerjaan yang belum mempunyai solusi kepada pimpinan.

7. Menyampaikan saran, gagasan, atau pendapat kepada pimpinan.

8. Adanya koordinasi seputar kerjaan bagi semua divisi agar teroganisir. 
9. Saling bertukar informasi tentang rencana atau kegiatan yang akan dilakukan setiap divisi.

10. Adanya kerjasama yang baik antar divisi untuk menjalin baik dan mempunyai solusi ketika terjadi masalah.

Indikator dari Motivasi Kerja yang diteliti adalah sebagai berikut:

1. Karyawan merasa fasilitas di tempat kerja mendukung dalam melakukan pekerjaan.

2. Karyawan merasa gaji yang diberikan cukup untuk memenuhi kebutuhan hidup.

3. Karyawan mendapat asuransi kesehatan.

4. Karyawan merasa aman jika harus pensiun karena mendapatkan tunjangan pensiun.

5. Sesama karyawan saling memiliki hubungan yang baik dalam pekerjaan maupun hubungan pribadi.

6. Karyawan merasa diterima oleh lingkungan kerjanya.

7. Karyawan mendapatkan pujian ketika hasil kerjanya memuaskan.

8. Karyawan diberikan bonus / penghargaan terhadap prestasi kerja yang dicapai.

9. Karyawan merasa bangga akan dirinya ketika bisa menyelesaikan tugas yang menantang.

10. Karyawan merasa dirinya diterima dan diakui ketika bisa menyelesaikan tugas yang dianggap sulit atau berhasil melaksanakan pekerjaan yang membutuhkan kreativitas yang tinggi.

Dalam mengolah data, peneliti menggunakan program SPSS versi 21 tahun 2012 dengan melakukan berbagai uji yaitu:

Uji Analisis Regresi

Analisis regresi adalah salah satu alat yang dapat digunakan untuk mengetahui pengaruh dari satu variabel bebas terhadap variabel tak bebas. Tujuannya adalah untuk meramalkan atau memprediksikan besaran dari nilai variabel tak bebas yang dipengaruhi oleh variabel bebas.

Dalam melakukan uji analisis regresi, pada variabel $\mathrm{X}$ dalam uj analisis regresi yang pertama, didapatkan hasil bahwa ada 3 pernyataan dalam variabel $\mathrm{X}$ yang tidak valid, sehingga dilakukan uji analisis regresi ke-2 dan didapatkan bahwa seluruh pernyataan dinyatakan valid.

\section{Uji Koefisien Determinasi}

Koefisien determinasi digunakan untuk menghitung pengaruh satu variabel terhadap variabel lainnya (Sugiyono, 2012). Hasil perhitungan koefisien determinasi dalam bentuk presentase.

\section{Uji T}

Uji T dilakukan untuk mengetahui apakah hipotesis diterima atau ditolak. Hasil dilihat dari tabel koefisien regresi dan dilihat di tabel t. Jika nilai yang thitung lebih besar dari $t$ tabel, maka hipotesis diterima, tetapi jika nilai thitung dibawah atau lebih kecil dari t tabel, maka hipotesis ditolak. 


\section{Hasil Temuan dan Diskusi}

Tabel 1.

\begin{tabular}{cccccc}
\hline \multirow{2}{*}{ Model } & \multicolumn{2}{c}{$\begin{array}{c}\text { Unstandardized } \\
\text { Coefficients }\end{array}$} & $\begin{array}{c}\text { Standardized } \\
\text { Coefficients }\end{array}$ & t & \multirow{2}{*}{ Sig. } \\
\cline { 2 - 4 } & $\mathrm{B}$ & Std. Error & Beta & & \\
\hline (Constant) & 2.642 & .588 & & 4.490 & .000 \\
Komunikasi Organisasi & .342 & .154 & .321 & 2.221 & .032 \\
\hline
\end{tabular}

$$
\begin{aligned}
& Y=a+b \cdot X \\
& Y=2,642+0,342 X
\end{aligned}
$$

Berdasarkan tabel di atas, Y (Motivasi Kerja) merupakan variabel dependen dan $\mathrm{X}$ (Komunikasi Organisasi) merupakan variabel independen. Konstan 2,642 menyatakan bahwa ketika Komunikasi Organisasi atau sama dengan 0, maka nilai Motivasi Kerja adalah 0,342. Variabel Y menyatakan jika setiap perubahan dari satuan nilai dari $\mathrm{X}$ akan memberikan perubahan sebesar 0,342 pada $\mathrm{Y}$.

Tabel 2.

\begin{tabular}{ccccc}
\hline Model & $\mathrm{R}$ & R Square & Adjusted R Square & $\begin{array}{c}\text { Std. Error of the } \\
\text { Estimate }\end{array}$ \\
\hline 1 & .321 & .103 & .082 & .446 \\
\hline \multicolumn{4}{c}{$\mathrm{KD}=r^{2} \times 100 \%$} \\
\end{tabular}

Berdasarkan hasil perhitungan di atas, disimpulkan bahwa pengaruh variabel X (Komunikasi Organisasi) terhadap variabel Y (Motivasi Kerja) adalah sebesar 10,3\% dan $89,7 \%$ sisanya merupakan faktor diluar penelitian yang dilakukan oleh penulis.

Analisis

Berdasarkan kuesioner yang sudah disebar dan hasil penelitian yang sudah diolah, peneliti dapat menarik kesimpulan bahwa adanya pengaruh Komunikasi Organisasi terhadap Motivasi Kerja Karyawan di Blibli.com. Pengaruh yang terjadi bersifat positif yang artinya jika nilai komunikasi organisasi naik maka nilai dari motivasi kerja juga naik.

Melalui hasil uji analisis regresi linear, dapat diketahui bahwa pengaruh yang diberikan oleh komunikasi organisasi terhadap motivasi kerja sebesar 0,342. Sehingga setiap ada 1 kenaikan dari nilai komunikasi organisasi, nilai motivasi kerja bertambah 0,342 .

Berdasarkan perhitungan, hubungan antara komunikasi organisasi dengan motivasi kerja karyawan di Blibli.com hanya sebesar 10,3 persen dan 89,7 persen lainnya merupakan faktor yang tidak diteliti oleh peneliti. Hal ini terjadi karena komunikasi organisasi yang terjadi di dalam perusahaan tidak terlalu efektif. Para karyawan hanya akan melakukan aktivitas komunikasi jika memang ada hal yang mendesak dan perlu di komunikasikan, diluar dari hal tersebut para karyawan hanya sebatas bertegur sapa jika bertemu.

Motivasi kerja para karyawan sendiri bisa meningkat jika ada faktor-faktor dari perusahaan yang mendukung seperti fasilitas yang disediakan, gaji yang mencukupi, 
dan pengakuan atas keberhasilan seorang karyawan. Seperti dalam teori motivasi yang disebutkan oleh Abraham Maslow bahwa terdapat lima tingkatan motivasi seseorang, dimulai dari kebutuhan fisiologis, rasa aman, hingga aktualiasi diri. Hal ini dapat disimpulkan berdasarkan hasil perhitungan diatas.

\section{Simpulan}

Dalam uji koefisien korelasi, terdapat pengaruh yang positif antara komunikasi organisasi dengan motivasi kerja karyawan sebesar 0,342 yang artinya setiap ada perubahan dari komunikasi organisasi, mempengaruhi motivasi kerja sebesar 0,342, pengaruh ini bisa dikatakan lemah dikarenakan memang para karyawan tidak terlalu terlibat komunikasi di dalam pekerjaan mereka. Mereka akan melakukan komunikasi ketika memang ada suatu hal yang harus di diskusikan.

Jika dihitung berdasarkan presentase, hanya sebesar $10,3 \%$ komunikasi organisasi bisa mempengaruhi motivasi kerja karyawan di Blibli.com dan 89,7\% lainnya merupakan faktor yang tidak diteliti oleh peneliti. Faktor tersebut bisa saja berupa kebutuhan pribadi, faktor keluarga, dan lainnya,

Hal ini juga sudah dibuktikan berdasarkan hasil uji hipotesis dimana uji ini dilakukan untuk membuktikan apakah hipotesis ditolak atau diterima. Hasil uji hipotesis ini dilihat dari nilai t hitung untuk nilai konstan (Motivasi Kerja) adalah sebesar 4,490 dan untuk $X$ (Komunikasi Organisasi) adalah sebesar 2,221 yang memiliki arti kedua nilai tersebut lebih besar dari t tabel, sehingga dapat diketahui bahwa hipotesis Ha diterima, yaitu terdapat pengaruh komunikasi organisasi terhadap motivasi kerja karyawan di Blibli.com.

\section{Ucapan Terima Kasih}

Penulis ingin mengucapkan terima kasih kepada seluruh responden, yaitu karyawan Blibli.com karena sudah meluangkan waktu untuk mengisi kuesioner penelitian ini. Penulis juga mengucapkan terima kasih kepada dosen pembimbing yang sudah membimbing peneliti selama satu semester dan juga seluruh rekan diskusi di Fakultas Ilmu Komunikasi.

\section{Daftar Pustaka}

Anwar Prabu Mangkunegara. (2013). Sumber Daya Manusia Perusahaan. Bandung: Remaja Rosdayakarya.

Intan, Wiranti. (2014). Pengaruh Komunikasi Organisasi Terhadap Motivasi Kerja Karyawan di Software Laboratory Center Universitas Bina Nusantara. Jakarta: Universitas Bina Nusantara

Kriyantono, Rachmat. (2012). Teknik Praktis Riset Komunikasi. Jakarta: Kencana Prenada Media.

Pace, R. W., \& Don F. Faules. (2011). Komunikasi Organisasi. Bandung: Remaja Rosdakarya.

Saraswati, Anindita. (2015). Pengaruh Kualitas Sistem, Kualitas Informasi, dan Kualitas Layanan Terhadap Loyalitas Pelanggan Melalui Kepuasan Pelanggan Pada Situs Commerce Blibli.com. Bandung: Universitas Telkom.

Siregar, Syofian. (2013). Metode Penelitian Kuantitatif. Jakarta: Kencana Prenada Media. 
Giovani Chieristian, Diah Ayu Candraningrum: Pengaruh Pola Aliran Komunikasi Organisasi

Terhadap Motivasi Kerja Karyawan di Blibli.com (Studi Kasus Divisi IT)

Sugiyono. (2011). Metode Penelitian Kuantitatif Kualitatif dan R\&D. Bandung: Alfabeta.

Susanto, E. H. (2009). Keanekaragaman Masyarakat dan Komunikasi Organisasi (Tinjauan Terhadap Dinamika Organisasi Pemerintahan di Daerah). Jakarta. Universitas Tarumanagara.

West, R., \& Lynn H. Turner. (2008). Pengantar Teori Komunikasi: Analisis Dan Aplikasi (Buku 1, Edisi ketiga). Terjemahan Maria Natalia Damayanti Maer. Jakarta: Salemba Humanika.

Wibowo. (2013). Manajemen Kinerja (Edisi Ketiga). Jakarta: PT Raja Grafindo Persada. 